\title{
COLOR CHANGE AND LIFE HISTORY OBSERVATIONS OF THE SPIDER GEA HEPTAGON (ARANEAE: ARANEIDAE)
}

\author{
By Laura Elsa Sabath* \\ 2812-24th Street, Lubbock, Texas 794IO
}

With the great interest in orb webs and their makers at the present time (Witt, et al, 1968; Witt, ed., 1969) any observations on webs and habits of orb weavers of genera other than the ones (Araneus, Zygiella, Argiope and Uloborus) used currently by experimenters are of interest.

Although spiders of the genus Gea are widespread, with species in the subtropics and tropics around the world, no studies of life history or careful web observations of any species of $G e a$ have been made. Since $\mathrm{Gea}$ is believed related to the much larger Argiope (Levi, 1968), it was of interest to see whether Gea species have similar habits, as resting in the center of the web and building a stabilimentum (a zigzag swatch of silk above and below the hub), and whether they made a similar eggcase. Levi (1968) reviews our limited knowledge of Gea as follows: the web is vertical with a dense viscid spiral and apparently without a stabilimentum; it is probably made in low vegetation and the spider drops from it when slightly disturbed.

\section{Material and Methods}

An adult female Gea heptagon (Hentz) was found October 19, 1968, on her web in 1o inch $(25 \mathrm{~cm})$ grass of a suburban yard, Portsmouth, Virginia. She was placed in an indoor terrarium and observed until she died November 7. During this time she spun webs, fed, and made two eggsacs, from both of which spiderlings hatched.

I kept the spider in a IO gallon (45 l) glass terrarium sealed with clear plastic wrapping. An open culture bottle with emerging fruit flies (Drosophila) supplied abundant food. Damp paper towels maintained high humidity. A hoop $20 \mathrm{~cm}$ in diameter stood on a

\footnotetext{
*The research is a product of Public Health Service Research Grant AI-01944 to H. W. Levi, Mus. Comp. Zool., Harvard Univ., from the National Institute of Allergy and Infectious Diseases.

I thank Dr. Levi for suggesting that I observe this species, for encouragement, and for help in preparing the manuscript, and Mr. Phil Morrison of the Norfolk Museum of Arts and Sciences, Norfolk, Virginia, for photography.

Manuscript received by the editor July 12, 1969.
} 

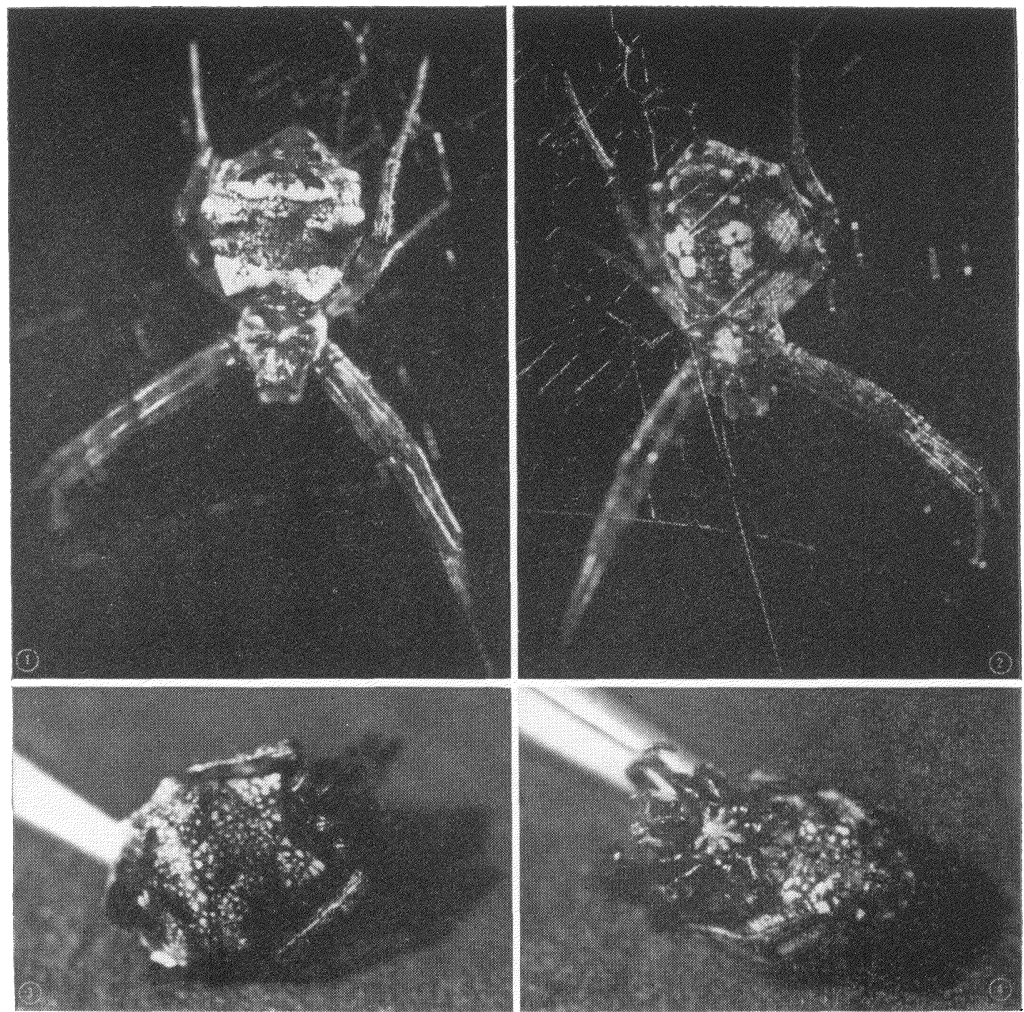

Figs. 1-4. Color change, in Gea heptagon, total length of the spider's body is about $5.5 \mathrm{~mm}$. 1. Dorsal view of female on web. 2. Ventral view of female on web. 3. Dorsal view of female after dropping from web. 4. Ventral view of female after dropping from web. 
wooden leg in the center of the terrarium floor. I set the vial holding the spider at its base. The spider usually climbed upward onto the hoop where she would spin her web. I collected webs easily after the spider dropped out by removing one hoop and providing another. The terrarium sat at room temperature near a window and fluorescent lights.

Specimens used are deposited in the Museum of Comparative Zoology, Harvard University.

\section{Observations}

Dropping and Color Change. The spider dropped from her web to the ground in the yard when first approached, but soon returned. For several days in the terrarium she dropped readily on approach, but later waited until touched with forceps. On the web, especially in direct sunlight, her abdomen was mottled with areas of creamy white that contrasted with brown markings that include a dark dorsal triangle (Figs. I-2). When she dropped to lie, legs folded, on the ground, the white areas turned instantly to brown often almost as dark as the dorsal triangle (Figs. 3-4). The white marks returned gradually over several minutes. The degree of change varied; the photographs unfortunately do not show the extremes seen.

$W e b$. The orb web in the grass was almost vertical. The diameter of the spiral was about $13 \mathrm{~cm}$; the hub was off center (Fig. 5). The webs in the terrarium were spun generally in the evening or early morning. They were not replaced nightly unless removed from the spider. Radii numbered from 25 to 33 ; spiral diameters varied from to to $12 \mathrm{~cm}$. None had a stabilimentum (Fig. 5). One evening I noted a complete orb that, an hour later, was missing a $60^{\circ}$ wedge from the lower side. Both radii and spiral were gone. Several other webs spun in captivity also were missing this wedge. In spinning the sticky spiral, the spider felt for the previous strand with leg I, sometimes putting leg 4 on it. She used leg 4 toward the hub for putting slack into the thread.

Feeding. I observed that when feeding on a leafhopper on the web in the field, she refused to drop from the hub until nudged hard by a vial edge. In the terrarium when I blew upon a web, she shook it violently. Once when a leafhopper fell into the web, she jerked it once, then again. When the prey moved, she ran toward it; the prey froze and she turned away. I wiggled the prey with forceps and the spider jumped it. It appeared instantly covered with silk. The spider wrapped it three or four turns, cut it loose, 


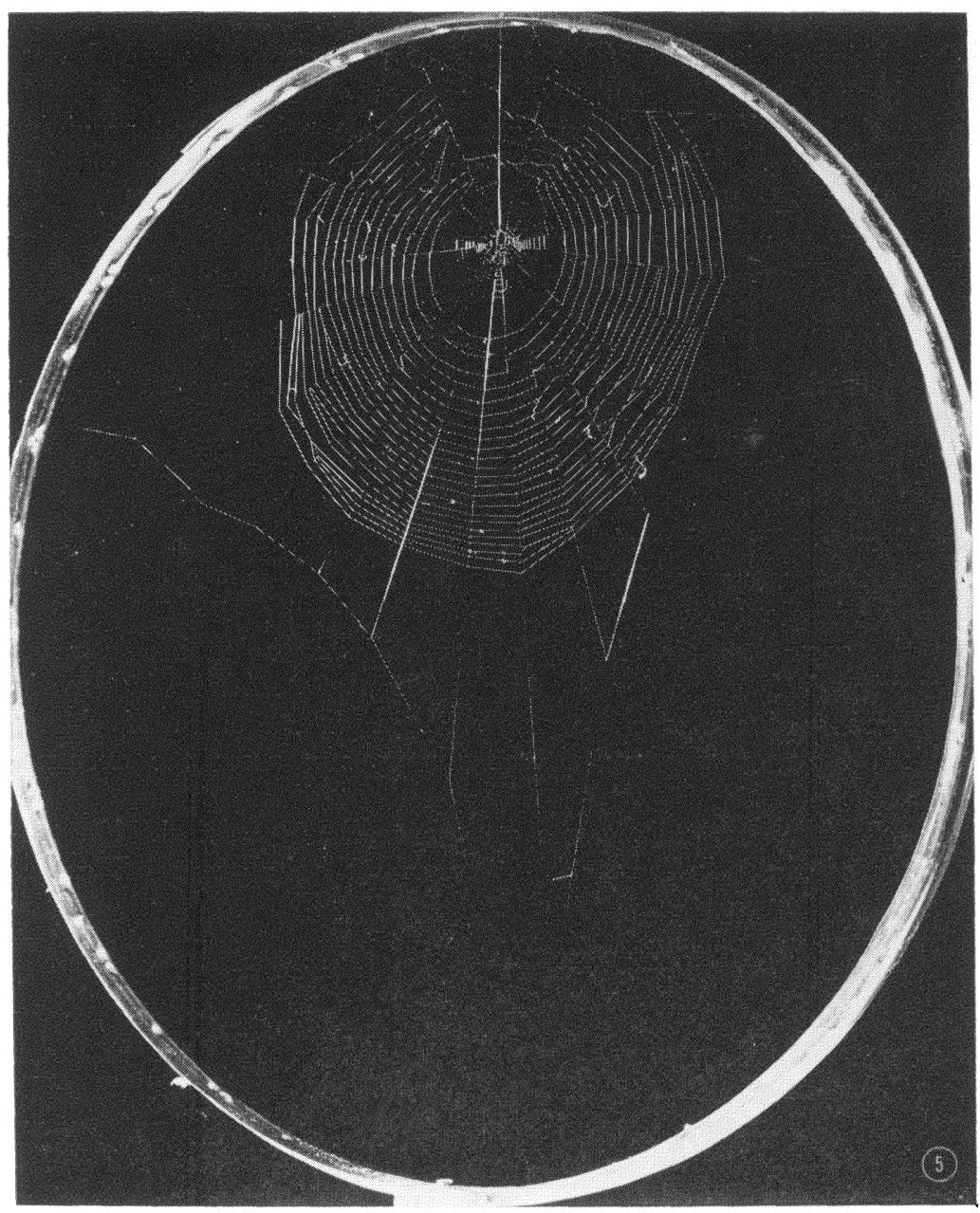

Fig. 5. Web in hoop. Tufts visible are dust. Missing sector at 12 o'clock is due to damage and partial repair. Hoop is about $20 \mathrm{~cm}$ across, the web $13 \mathrm{~cm}$. 
repaired the radii, carried the prey to the hub, wrapped it two or three more turns, and began feeding. Another day she shook the web when a leafhopper dropped into it. She ran to the prey, hesitated, then enswathed, wrapped and bit it. She returned to the hub and bobbed several times, just enough to shake the prey. She remained quietly at the hub about a minute, then returned to cut the prey loose, repaired the radii, carried the prey to the hub and began feeding. Once when the spider had completed two-thirds of the sticky spiral, a fruit fly landed in the finished portion. She ignored it, finished the web, sat on the hub about two seconds, and then went to the fly. She tore it from the web, did not repair the web, tore more web by dragging the fly to the hub, wrapped it there and began feeding. She usually threw prey remains well away from the web.

Eggsacs. I found an eggsac in an upper corner of the terrarium on the morning of October 23, about $30 \mathrm{~cm}$ from the web, as far from the web as space allowed. A supporting tangle web formed a thin sparse barrier around it; the sac hung inside in a hollow area about $3 \mathrm{~cm}$ across. The sac itself (Fig. 6) was flattened and resembled a dried broken leaf; its longest dimension was $13 \mathrm{~mm}$. The more exposed side was suspended by about nine threads from the eggsac corners and one from the bulging center; the color was ivory with streaks of dark silk. Under the microscope the dark strands appeared superimposed on the sac wall; they gave the impression of camouflage. The less exposed side (facing the terrarium corner but $1.5 \mathrm{~cm}$ from it) was tacked to the exposed side; the seams were easily opened. This side was lighter ivory without the dark streaks. A similar eggsac was made ten days later, November I, in another corner.

Spiderlings. The evening of November IO, I9 days after the first eggsac was made, I put it in a vial which lay under a bright light. Several hours later I noticed spiderlings emerging from breaks in the eggsac seam. With a dissecting microscope I saw those inside biting threads but did not see any silk-dissolving fluid on them. Fortyfive black-and-white spiderlings emerged (Fig. 7); no undeveloped eggs or embryos were left inside. I opened the eggsac made November I, ten days earlier, and found 30 eggs or embryos (eggs with white leg-lines). The following day 20 hatched into translucent white spiderlings; 8 remained eggs with no sign of development; 2 were lost.

On August 25, I968, I found 22 Gea in sweeping one grassy locality just south of Portsmouth (North Carolina, Camden Co., 

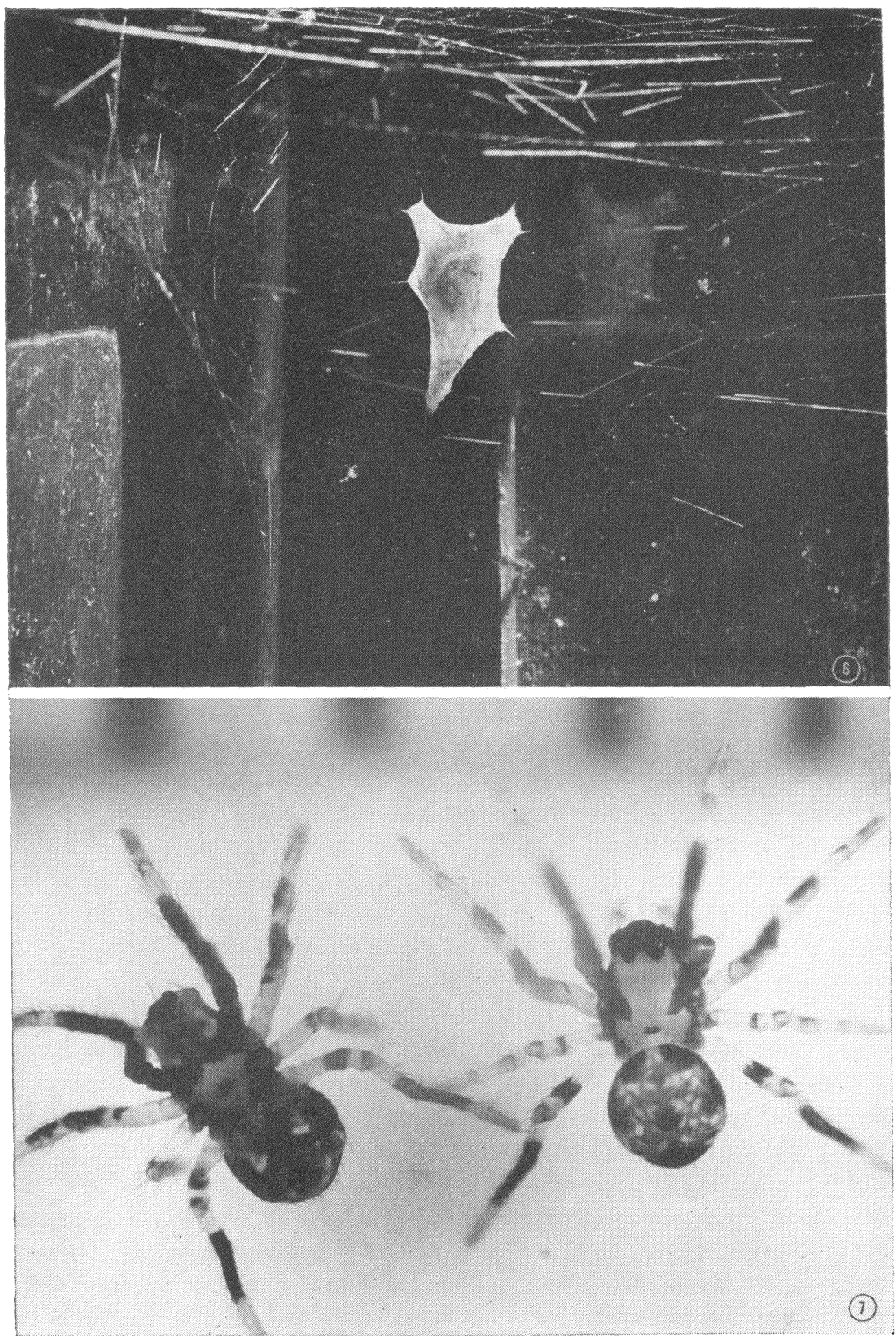

Fig. 6. Eggsac, $13 \mathrm{~mm}$ long.

Fig. 7. Spiderlings newly emerged from eggsac showing juvenile pattern. Bars above are $1 \mathrm{~mm}$ apart. 
7 m.. S of South Mills). They include 2 females, 2 juvenile females, I male, 7 juvenile males of various sizes, and Io small juveniles. The prolateral edge of the patella and tibia of the smallest juvenile measures a little over $0.6 \mathrm{~mm}$, whereas that of the emerged spiderlings of the first eggsac average a little less than 0.5 $\mathrm{mm}$. Adults measure around $2.5-3.0 \mathrm{~mm}$. The smallest field juvenile is probably only one molt ahead of the emerged spiderlings. Therefore I assume that Gea normally emerge at this locality in the fall and presumably overwinter as juveniles. Another possibility, considering the wide range of development found in field collections, is that at least more southern Gea produce more than one generation per year.

\section{Discussion}

Gea heptagon makes a vertical web in grass. As in species of Argiope, the spider rests in the center of the web, but no stabilimentum has been observed. Unlike Argiope, the spider readily drops out of the web when disturbed. Most unusual is the sudden change of color when dropping from the web.

I have found reports of rapid color change in only four other spiders. Bristowe ( 1958, p. 264) observed the linyphiid Floronia bucculenta drop to the ground when disturbed and turn white abdominal areas to brown. He states that under the microscope white intestinal guanin cells contract rapidly to expose the brown body fluid when the spider is shaken; the cells take several minutes to expand again. He was told by N. L. Roberts in Australia of an araneid, Phonognatha wagneri, that reacts similarly. Uyemura (1957) reports color changes for the golden green tetragnathid Leucauge subgemma and the golden yellow theridiid Argyria venusta [=Chrysso venusta]. In both "when picked [up] or shaken strongly [out of the web]" the color breaks up into numerous star-like flecks. As in the Gea heptagon observed, the spiders darken instantaneously but recovery to normal takes several minutes.

Of interest also is the open sector occasionally found on the lower part of Gea's web. Open sectors are found in the upper part of the web of $Z$ ygiella, perhaps facilitating rapid descent from the retreat above it to the hub. The open sector in the web of Gea heptagon might also be an adaptation to the habit of dropping out of the web on disturbance. 
BRISTOWE, W. S.

\section{REFERENCES}

1958. The World of Spiders. Collins, London.

LEvi, H. W.

1968. The spider genera Gea and Argiope in America (Araneae: Araneidae). Bull. Mus. Comp. Zool. 136(9): 319-352.

Uyemura, $T$.

1957. Colour change of two species of Japanese spiders. Acta Arachnol. 15: 1-10. [In Japanese with English summary].

WITT, P. N. ed.

1969. Web building spiders, a symposium. Amer. Zool. 9: 70-238.

WitT, P. N., C. F. Reed and D. B. Peakall

1968. A Spider's Web. Springer Verlag, New York. 

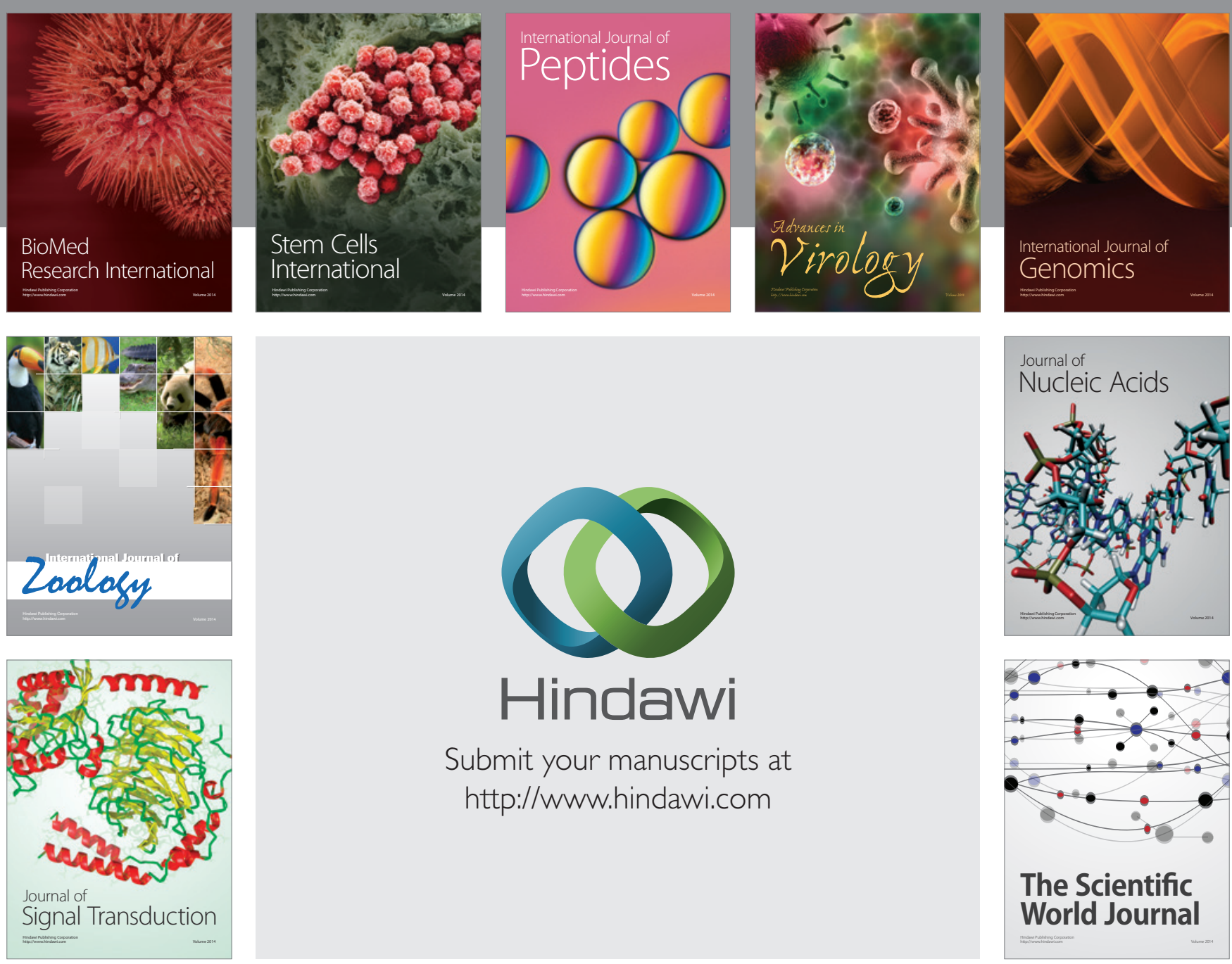

Submit your manuscripts at

http://www.hindawi.com
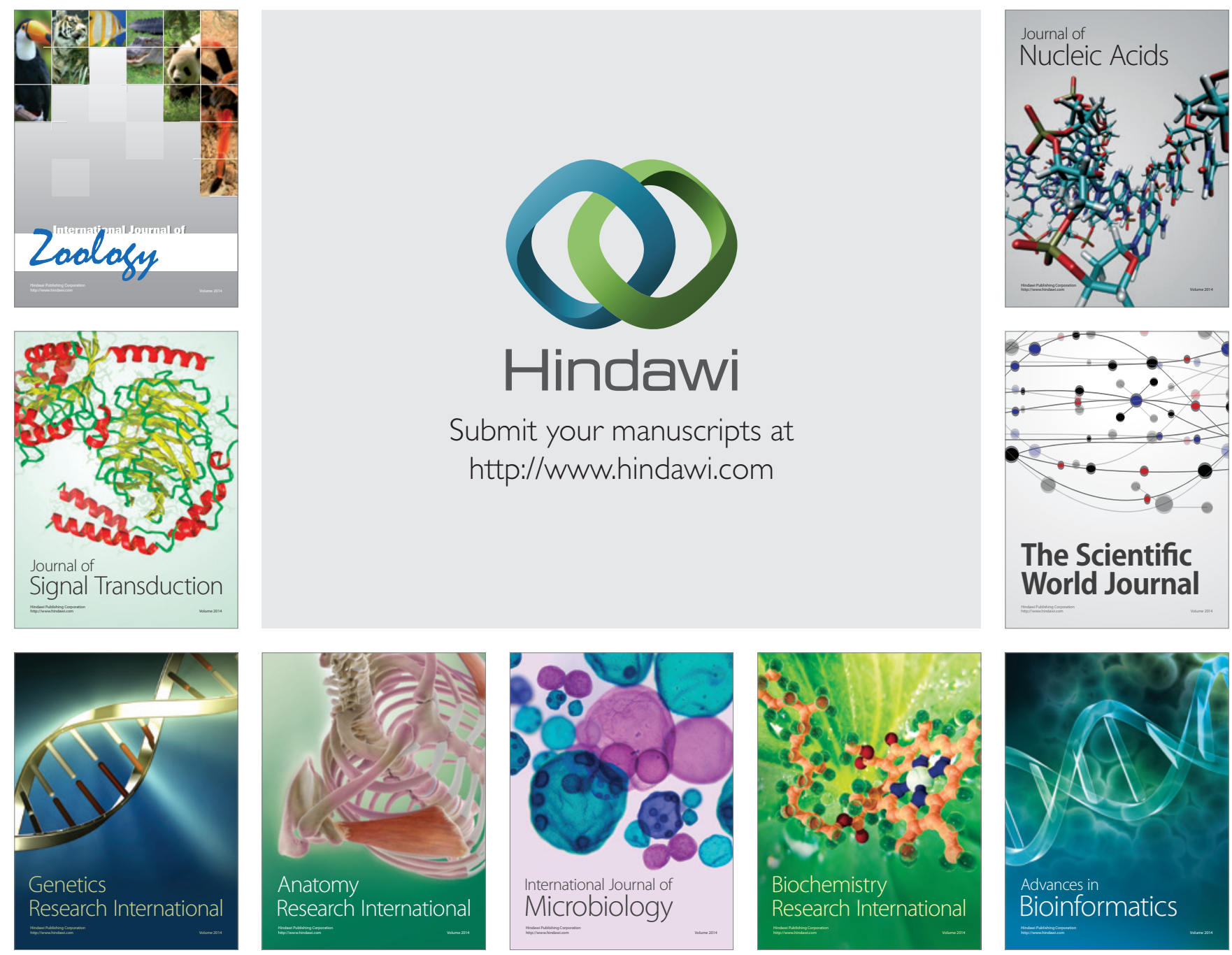

The Scientific World Journal
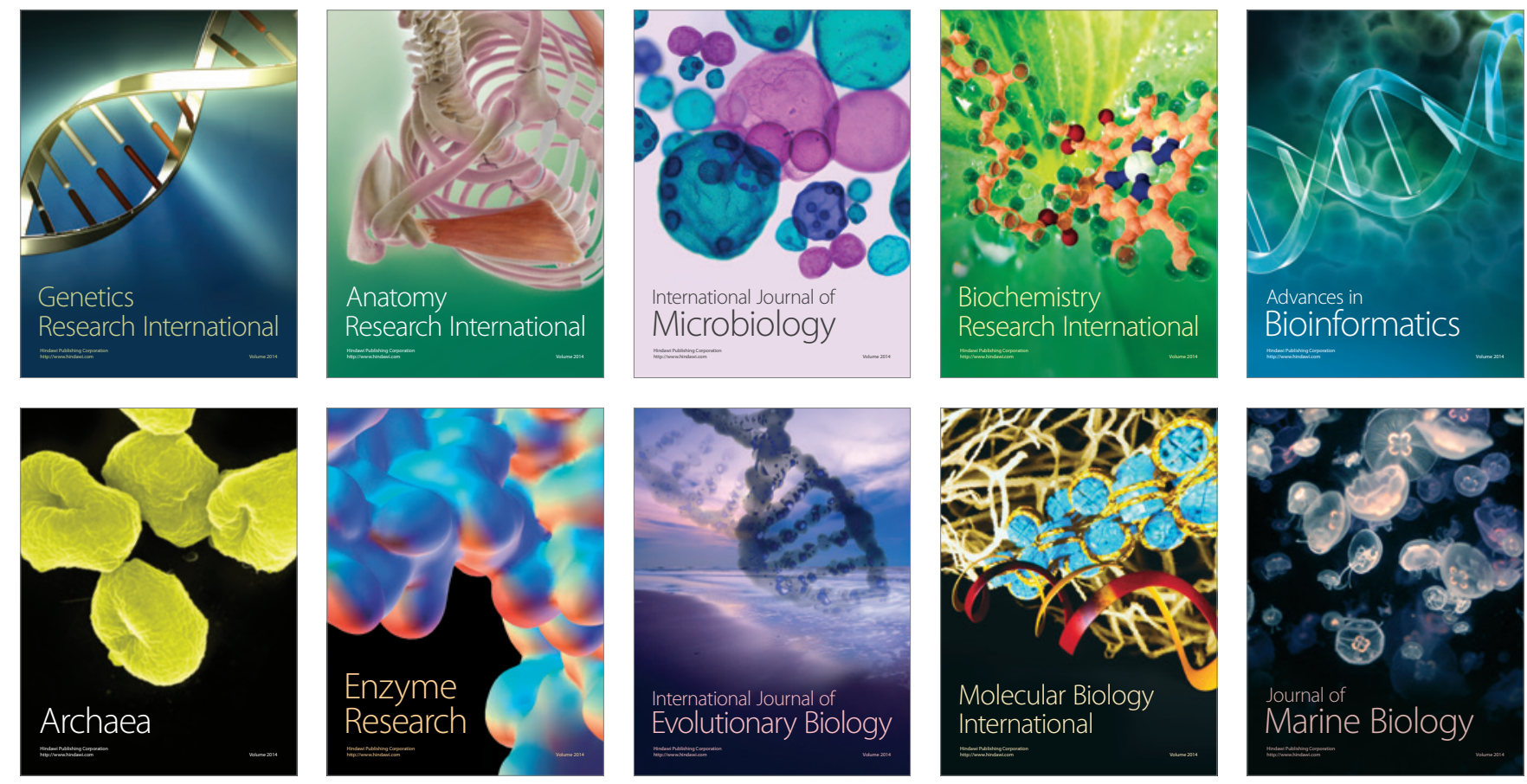